\title{
Long-term outcome of surgical correction of congenital kyphosis in patients with myelomeningocele (MMC) with segmental spino-pelvic fixation
}

Authors Josh E Schroeder, Yair Barzilay, Amir Hasharoni, Leon Kaplan Institution Spine Unit, Hadassah-Hebrew University Medical Center, Jerusalem, Israel

\begin{tabular}{|c|c|}
\hline $\begin{array}{l}\text { Methods evaluation and } \\
\text { class of evidence (CoE) }\end{array}$ & \\
\hline \multicolumn{2}{|l|}{ Study design: } \\
\hline \multicolumn{2}{|l|}{ Prospective cohort } \\
\hline \multicolumn{2}{|l|}{ Retrospective cohort } \\
\hline \multicolumn{2}{|l|}{ Case control } \\
\hline Case series & - \\
\hline \multicolumn{2}{|l|}{ Methods } \\
\hline $\begin{array}{l}\text { Patients at similar point in } \\
\text { course of treatment }\end{array}$ & • \\
\hline Follow-up $\geq 85 \%$ & - \\
\hline $\begin{array}{l}\text { Similarity of treatment } \\
\text { protocols for patient groups }\end{array}$ & - \\
\hline $\begin{array}{l}\text { Patients followed-up long } \\
\text { enough for outcomes to occur }\end{array}$ & \\
\hline $\begin{array}{l}\text { Control for extraneous } \\
\text { risk factors }\end{array}$ & $\begin{array}{l}\text { Not } \\
\text { available }\end{array}$ \\
\hline Overall class of evidence & IV \\
\hline \multicolumn{2}{|c|}{$\begin{array}{l}\text { The definiton of the different } \\
\text { classes of evidence is available on } \\
\text { page } 63 \text {. }\end{array}$} \\
\hline
\end{tabular}

\section{ABSTRACT}

Study design: A retrospective case series of patients with myelomeningocele (MMC) who underwent kyphectomy and posterior segmental fixation using Luque rods and 16-gauge wires.

Objective: To assess outcomes after posterior kyphectomy and segmental fixation for kyphosis in patients with MMC.

Methods: Thirteen consecutive patients who underwent posterior kyphectomy for transforaminal fixation contiguous to "everted lamina." Fusion rates, time to fusion, change in Cobb angle, complications, and improvement in activities of daily living using the Katz score were measured.

Results: Average age at time of surgery was 9.2 (range, 4.5-17) years. Average time to follow-up was 120 (range, 20-310) months. Solid fusion was achieved in 9 patients $(69 \%)$ with a mean time to fusion of 12 months. The mean postoperative kyphotic curve was $22^{\circ}$ with an average correction of $90^{\circ}$. Five patients $(38 \%)$ experienced a postoperative complication. The mean improvement in activities of daily living score was 1.6 points and all patients achieved independent sitting balance.

Conclusion: Segmental spino-pelvic fixation is a solid alternative mode of fixation in patients with MMC with congenital kyphosis. Patient selection, proper perioperative multidisciplinary assessment, and surgeons' expertise are significant in the success of this complex surgery. 


\section{STUDY RATIONALE}

Thoracolumbar kyphosis occurs in $10-20 \%$ of patients with myelomeningocele (MMC) [1-3].

Curves are congenital and rigid, larger than $80^{\circ}$ at birth and progressing to more than $100^{\circ}[4]$. These lead to chronic pressure sores, impaired sitting balance, collapsing spine phenomena, decreased abdominal capacity, and reduced respiratory function [4]. There is no consensus regarding the proper mode of correction in patients with MMC [5].

\section{OBJECTIVE}

To present the long-term results of a segmental spinopelvic fixation method for correction of congenital thoracolumbar kyphotic deformities in patients with MMC using Luque rods and neuroforaminal wires.

\section{METHODS}

Study design: Retrospective case series (all medical records of the children were reviewed).

\section{Inclusion criteria:}

- Thoracic level MMC (T6-T12) and congenital rigid kyphotic deformity

- All patients referred for surgical correction at one institution

- A patent ventriculoperitoneal shunt

\section{Exclusion criteria:}

- Active skin or urinary tract infection

- Inadequate nutritional status (albumin levels within normal age correlated levels)

\section{Patient population:}

- Thirteen consecutive patients meeting study criteria

- All patients were paraplegic from MMC level down

- All patients had skin scarring from abrasions or lacerations on the apex of the deformity

\section{Surgical technique:}

- Patients were placed on specialized silicon cushions and prepared for a posterior approach.

- A posterior longitudinal incision was executed and dissection of the soft-tissue flap was kept as thick as possible. The dural sac was released, ligated, cut, and removed at the level of the MMC. A kyphectomy was performed (Figs 1-6).

- Fixation started four or five segments above the beginning of the deformity down to the sacrum using the Galveston technique [1] (Fig 3).

- A local bone graft is added to sides of vertebrae to induce fusion.

- Patients were placed in a tailor-made jacket until bony fusion was evident.

- Further detail is provided in the web appendices.

\section{Outcomes:}

Standard x-rays were performed every 6 to 8 weeks to evaluate:

- Fusion rate-fusion defined as connecting vertebrae in the lateral view and a bony mass on the sides of the bifid vertebrae uniting the two vertebrae in the anteroposterior view

- Time to fusion-defined as the first $\mathrm{x}$-ray with evidence of fusion

- Change in the Cobb angle (comparing preoperative with postoperative Cobb angles)

- Complication rates

- Functional outcomes using:

- Katz independence in activity of daily living (ADL) score [6]. A scale of 0-6 points testing patient independence in bathing, dressing, toileting, transferring, continence, and feeding. A patient gets 1 point for each activity he/she is unable to perform. The higher the score, the lower the function. Independence in ADLs suggested as a score of 0 to 1 point

- Sitting position-assessed as either independent or needing hand-hold support

\section{Analysis}

Descriptive statistics were performed including mean \pm SD for continuous measures and frequency counts for categorical variables. 
Fig 1 Preoperative image of a child after being placed on the operating table; note two silicon rolls lowering pressures from the chest.

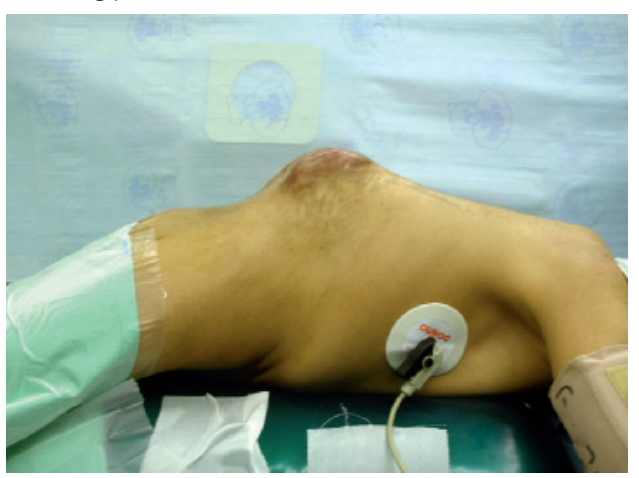

Fig 2 Preoperative $x$-ray of the spine in the kyphotic area.

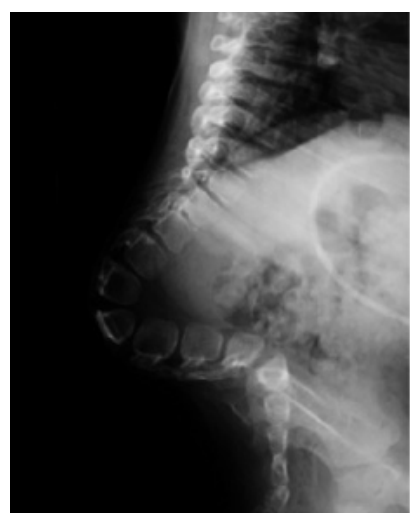

Fig 3 The spine after the kyphectomy, placement of rods and wires.

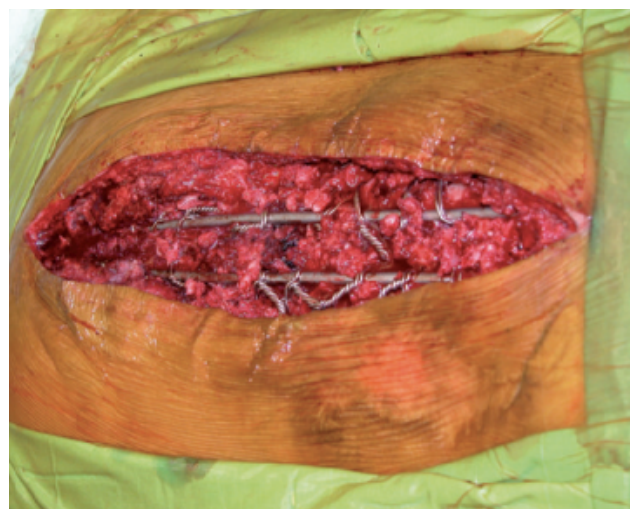

Fig 4 Postoperative $x$-rays of the spine.

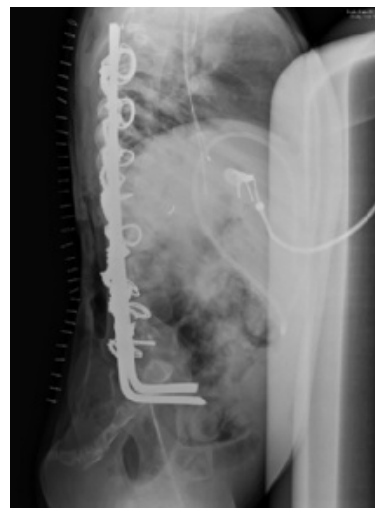

Fig 7 Model showing placement of rods.

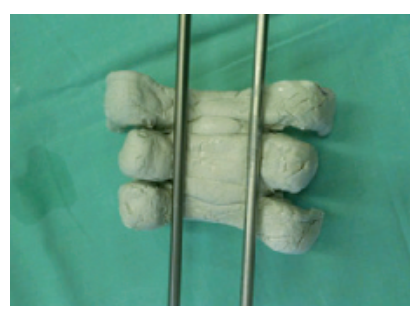

Fig 9 View from underneath.

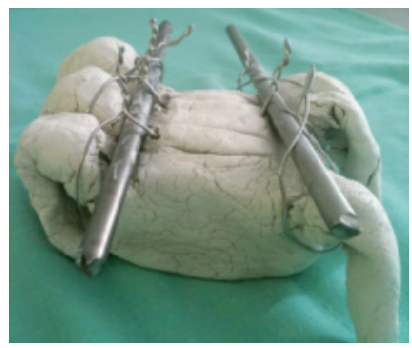

Fig 5 The child 2 years postoperatively.

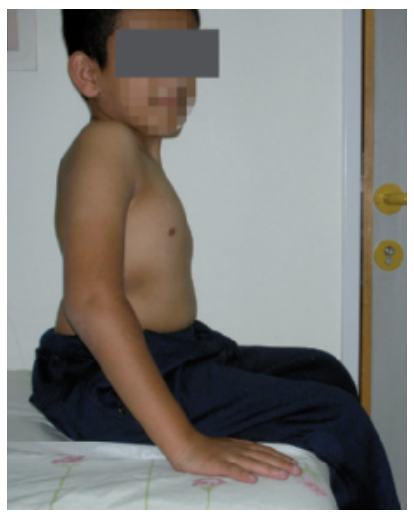

Fig 6 X-ray of the spine; 2 years postoperative fusion is seen at the level of the kyphosis.

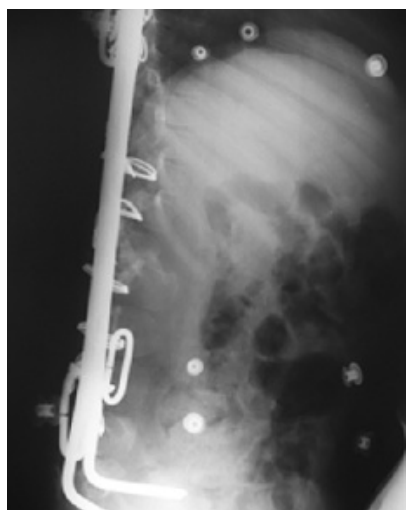

Fig 8a-b Model showing tightening of the wires.
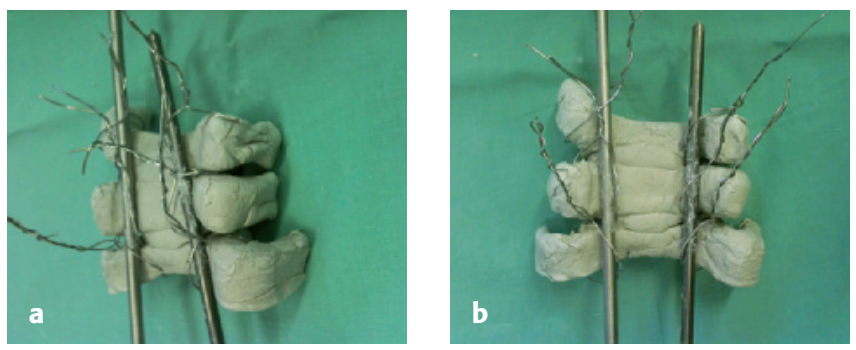

Fig 10 Final result.

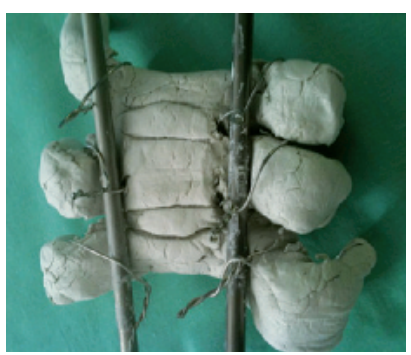




\section{RESULTS}

- All 13 patients were available for follow-up. Average time to final follow-up was 120 months (range, 20-310 months). Among the 13 subjects, 9 (69\%) were male. The average age at time surgery was 9.2 years (range, $4.5-17$ years) and average kyphosis was $108^{\circ}$ (range, 90-130) (Table 1).

- Nine patients (69\%) had a stable bony fusion. Mean time to fusion was 12 months (range, 9-16 months) (Fig 6). The mean postoperative kyphotic curve measurement was $22^{\circ}$ (range, $15-30^{\circ}$ ) (Fig 4). The average correction was $90^{\circ}$ (range, $70-100^{\circ}$ ). There was a mean secondary loss of correction of $7-10^{\circ}$ until fusion was noted.
- Five patients (38\%) suffered from postoperative complications-one infection and four implant-related complications (see web appendix). There was no documentation of postoperative pressure sores.

- The Katz ADL [6] score improved by an average of 1.6 (mean, 2; range, 0-3: $\mathrm{SD}=0.8$ ) points.

- All patients achieved an erect, balanced sitting position allowing mobilization in wheelchairs and sitting in chairs without the need of hand support (Fig 5).

Table 1 Patients demographics, surgical characteristics, and length of follow-up for 13 consecutive patients.

\begin{tabular}{|c|c|c|c|c|c|c|}
\hline Patient No. & Age at surgery, y & Sex & Preoperative Cobb angle, degrees & Level of fixation & Katz score change & Follow up, mo \\
\hline 1 & 13 & $\mathrm{~F}$ & 95 & Thoracic 4-sacrum & 1 & 125 \\
\hline 2 & 7 & $\mathrm{~F}$ & 100 & Thoracic 3-sacrum & 2 & 120 \\
\hline 3 & 12 & M & 110 & Thoracic 3-sacrum & 1 & 110 \\
\hline 4 & 8 & M & 130 & Thoracic 2-sacrum & 2 & 110 \\
\hline 5 & 9 & M & 120 & Thoracic 2-sacrum & 3 & 90 \\
\hline 6 & 12 & M & 90 & Thoracic 3-sacrum & 2 & 87 \\
\hline 7 & 17 & M & 115 & Thoracic 3-sacrum & 2 & 75 \\
\hline 8 & 8 & $\mathrm{~F}$ & 110 & Thoracic 4-sacrum & 1 & 73 \\
\hline 9 & 5 & M & 108 & Thoracic 5-sacrum & 1 & 60 \\
\hline 10 & 4.5 & M & 105 & Thoracic 5-sacrum & 0 & 55 \\
\hline 11 & 8 & M & 110 & Thoracic 2-sacrum & 2 & 90 \\
\hline 12 & 7 & M & 110 & Thoracic 3-sacrum & 2 & 36 \\
\hline 13 & 10 & $\mathrm{~F}$ & 95 & Thoracic 4-sacrum & 2 & 36 \\
\hline
\end{tabular}

Table 2 Method of fixation and complication rates comparing this study to other studies evaluating surgical fixation in patients with myelomeningocele.

\begin{tabular}{lclc}
\hline Study & No. of patients in study & Method of fixation & Rate of complication, \% \\
\hline Current study & 13 & Posterior & 38 \\
\hline Ko et al (2007) [8] & 9 & 7 posterior, 2 anterior and posterior & 89 \\
\hline Keessen et al (1992) [7] & 61 & Posterior, anterior and posterior & 73 \\
\hline Kocaoglu et al (2008) [9] & 7 & Posterior & 29 \\
\hline McCall (1998) [12] & 16 & Posterior & 50 \\
\hline Odent et al (2004) [15] & 9 & Anterior & 44 \\
\hline Lintner and Lindseth (1994) [11] & 34 & Posterior & 50 \\
\hline Niall et al (2004) [13] & 24 & 22 posterior, 2 anterior and posterior & 83 \\
\hline
\end{tabular}




\section{DISCUSSION}

- Correction of congenital kyphotic deformity in patients with MMC is challenging and has a high rate of complications. The goal of surgery is to provide them with a stable, balanced, and fused spine allowing balanced sitting, free mobilization and proper nutrition [3].

- Others have reported that the elimination of the need of an anterior approach reduces the morbidity of surgery $[17,18]$.

- The correction affects not only the children but also their parents and caretakers, with an improvement in ADLs and a subjective improvement in social status and improved self-image [10].

- Solid fusion was achieved in 9 patients (69\%), with a mean time to fusion of 12 months. This is shorter than previously published for similar surgery [12]. The complication rate in the presented series was $38 \%$, while in similar series it ranged 28-89\% (Table 2) [7-9, 11-13].

- Patients improved in their ADLs and were all independent at sitting after surgery. The tailor-made jacket worn by the patients reduces the strain on the rods and adjacent soft tissues, thus decreasing persistent skin break down [14]. Compliance with the brace was high; it was worn more than $90 \%$ of daytime.

- Strengths: The study evaluated consecutive patients with a long-term follow-up. A standardize ADL score was used to measure improvement. We performed frequent $\mathrm{x}$-rays to evaluate time to fusion.

- Limitations: This was a retrospective case series with a small number of cases and no comparison group. We cannot state that this method of treatment is more effective or safer than others.

For further discussion, see the web appendix at www.aospine.orglebsj.

\section{SUMMARY AND CONCLUSIONS}

- The long-term outcome of kyphectomy with long posterior segmental fixation provides for acceptable functional outcomes, a relatively low rate of manageable complications compared with other studies.

- The main cause of complications in these patients is hardware related.

- In most cases, requiring the need of hardware removal, keeping the brace on, and treating infections can result in stable fibrous union and with a balanced sitter.

Future studies are needed to compare this method with others to establish the evidence for safety and efficacy.

\section{REFERENCES}

1. Allen BL Jr, Ferguson RL (1986) Neurologic injuries with the Galveston technique of L-rod instrumentation for scoliosis. Spine (Phila Pa 1976); 11:14-17.

2. Apkon SD, Fenton L, Coll JR (2009) Bone mineral density in children with myelomeningocele. Dev Med Child Neurol; 51(1): 63-67.

3. Askin GN, Hallett R, Hare N, et al (1997) The outcome of scoliosis surgery in the severely physically handicapped child: an objective and subjective assessment. Spine (Phila Pa 1976); 22:44-50.

4. Furderer S, Hopf C, Schwarz M, et al (1999) Orthopedic and neurosurgical treatment of severe kyphosis in myelomeningocele. $\mathrm{Neu}$ rosurg Rev; 22:45-49.

5. Guthkelch AN (1986) Aspects of the surgical management of myelomeningocele: a review. Dev Med Child Neurol; 28(4):525-532.

6. Katz S, Ford AB, Moskowitz RW, et al (1963) Studies of illness in the aged. The index of ADL: a standardized measure of biological and psychosocial function. JAMA; 185:914-919.

7. Keessen W, van Ooy A, Pavlov P, et al (1992) Treatment of spinal deformity in myelomeningocele: a retrospective study in four hospitals. Eur J Pediatr Surg; 2(Suppl 1):18-22.

8. Ko AL, Song K, Ellenbogen RG, et al (2007) Retrospective review of multilevel spinal fusion combined with spinal cord transection for treatment of kyphoscoliosis in pediatric myelomeningocele patients. Spine (Phila Pa 1976); 32:2493-2501.

9. Kocaoglu B, Erol B, Akgülle H, et al (2008) Combination of luque instrumentation with polyaxial screws in the treatment of myelomeningocele kyphosis. J Spinal Disord Tech; 21(3):199-204.

10. Larsson EL, Aaro SI, Normelli HC, et al (2005) Long-term follow-up of functioning after spinal surgery in patients with neuromuscular scoliosis. Spine (Phila Pa 1976); 30:2145-2152.

11. Lintner SA, Lindseth RE (1994) Kyphotic deformity in patients who have a myelomeningocele: operative treatment and long-term follow-up. J Bone Joint Surg Am; 76(9):13011307.

12. McCall RE (1998) Modified luque instrumentation after myelomeningocele kyphectomy. Spine (Phila Pa 1976); 23:1406-1411.

13. Niall DM, Dowling FE, Fogarty EE, et al (2004) Kyphectomy in children with myelomeningocele: a long-term outcome study. J Pediatr Orthop; 24:37-44. 
14. Nolden MT, Sarwark JF, Vora A, et al (2002) A kyphectomy technique with reduced perioperative morbidity for myelomeningocele kyphosis. Spine (Phila Pa 1976); 27: 1807-1813.

15. Odent T, Arlet V, Ouellet J, et al (2004) Kyphectomy in myelomeningocele with a modified Dunn-McCarthy technique followed by an anterior inlayed strut graft. Eur Spine J; 13(3):206-212.

16. Simpson JL (1999) Fetal surgery for myelomeningocele: promise, progress, and problems. JAMA; 282:1873-1874.

17. Suk SI, Kim JH, Lee SM, et al (2003) Anterior-posterior surgery versus posterior closing wedge osteotomy in posttraumatic kyphosis with neurologic compromised osteoporotic fracture. Spine (Phila Pa 1976); 28: 2170-2175.

18. Weiss HR, Goodall D (2008) Rate of complications in scoliosis surgery: a systematic review of the PubMed literature. Scoliosis; 3:9.

\section{EDITORIAL STAFF PERSPECTIVE}

Case series rightfully remain next to the bottom of the evidence hierarchy. However, they can have merit for exceptional conditions or as a basic fact-finding investigation, especially when conducted in truly sequential fashion with consistent care application and appropriate long-term follow-up. Despite its limitation as case series, this article received favorable reviews for being interesting and commendable with excellent long-term follow-up of wound and hardware complications with a specific technique for a difficult clinical problem. The Katz functional outcome instrument was found to be applicable, relevant, and simple to use and a welcome expansion of the outcomes armamentarium.

The following limitations, which could not be resolved due to infrastructure and study design, were noted and could conceivably have enhanced the study further:

- Methodology of patient identifications and records review was not elucidated.

- The following complications common to this population were not discussed either because of incredible technique or the failure to document them:

- Urinary tract infection

- VP shunt malfunction

- CSF leak

- Hydrocephalus problems

- Neurogenic pain or symptoms

- Pneumonia
The only complications documented were related to hardware failure, nonunion, or wound complications.

- Were any patients excluded from this case series or did every patient with myelomeningocele and kyphosis meet the criteria?

- An attempt at comparison to other treatment groups would have elevated the status of this study tremendously, for instance assessment of patients treated nonoperatively, or assessment of surgical technique other than neuroforaminal wires. Now the prevailing question on every surgeon's mind after reading this article will be: how does this specific method of fixation compare to other options-pedicle screws, iliac bolts, hooks, or unit rods?

- The comparisons with other articles are appreciated; however an attempt to consolidate the variables looked at in those articles and an attempt to align them with the variables studied in this article more comprehensively would have been a welcome addition.

In conclusion, the article of Schroeder et al advances our knowledge base on this condition and refocuses our attention on the indication for which we operate, and raises the important question of relevance of high-tech implants to achieve optimal outcomes for specific conditions. 